College, and the writer can speak of their excellence since they have been adopted in his laboratory.

This, then, is the clinical chemist's vade-mecum to chromatography and electrophoresis; and it should be near the bench of everyone responsible for such work, because hardly a problem will arise in the management of the experiment which cannot be resolved by reference to it. Some of the advice may appear surprising-for example, that rather than using paper, electrophoresis on cellulose acetate supporting membranes should be the tyro's choice-but this is wholeheartedly supported by the writer's experience.

Neither part is really more important than the other; but the second volume, on electrophoresis, is especially valuable because for the first time within a single book are united detailed accounts of all the clinically useful techniques, including hæmoglobin separations, cellulose acetate, and gel electrophoresis with convenient immuno-diffusion techniques derived from those of Grabar and Williams and Ouchterlony; all are given in enough detail for a beginner.

Recently a morbid anatomist has claimed the hegemony over the more scientific branches of laboratory medicine, and thus unchained the medical equivalent of the Peloponnesian wars. These volumes alone might make him retract, for unless the anatomist has a universal intellect like Leonardo, he will find both technique and interpretation so difficult that he will be forced to resign his claim. These books alone show that biological chemistry has grown far beyond the limits of a 'pathological department', and needs its own department and direct access to the clinician even in quite small hospitals. It even seems possible that today chemists contribute more to the well-being of the patient than does the morbid anatomist.

\section{Clinical Medicine: The Modern Approach}

A. E. ClarK-Kennedy, M.A., M.D., F.R.C.P.; C. W. BARTley, M.A., D.M., M.R.C.P. Pp. $X+425$. London: Pitman Medical Publishing Co. Ltd. 1960. 25 s.

Two things are clear from the preface: this is not a textbook; it is meant rather to stimulate thinking, not to purvey knowledge. Many other things, too, will be much clearer than before to any medically inclined reader who follows the authors' instructions to read Part I first (The Patient and His Disease), 'skim quickly through' Parts II and III (Primary Functional Disorders, and Organic Disease), "just to get a line on what its all about' before tackling Part IV (Clinical Diagnosis) and Part V (Principles of Prevention and Treatment).

Emphasis is achieved by using heavy type to pass on headings in the course of the main descriptive sections on 'Primary Functional Disorders' and 'Organic Disease'. Then follows a brilliant series of chapters on the evolution of a Clinical Diagnosis. 'His Diseases' are described in relation to the interaction of genetic and environmental influences upon man's body-mind during the inevitable process of ageing. In this light a single cause for any human disease now seems improbable. Only a born teacher and a great clinician could dare to write a chapter on 'Making the Best of the Little Understood'. The final chapters on 'The Very Ill Patient' and 'The Dying Man' lift this book into a class by itself. Here medicine as the art is portrayed, taking over from the science, at this-as it does, too, at other-critical times during life's busy fever.

Yet even this book has its Persian faults, its Achilles' heel. On p. 112 the differences between resistance and immunity are not as clear as they might be. Infants have a high, not a low, resistance to some respiratory infections - such as measles. After repeated exposure to and reaction against infection, man develops ' immunity', not ' resistance '; the latter term should be reserved for the state of successful encounter before the body succumbs to infection, recovery from which is followed by an immune reaction. On p. 126 cleft palate should not be offered as a common example of a rubella defect, in place of deafness or cataract. On the next page it is scarcely correct to write that the virus of herpes febrilis never causes serious complications -for example, fatal encephalitis. While it is true, as on p. 128, to write that poliomyelitis is 'an acute infection of the nerve cells... of the spinal cord', there is need also to state that poliovirus infection, upon which the spread of this disease depends, occurs primarily in the human gut. That the gut infection is symptomless then makes sense of the unrecognized and undiagnosed ' cases' which spread infection widely during epidemics.

Enough of pin-pricking. It is a fine book whose sub-title might well have been: 'A Prelude to Medical Practice'.

\section{Medical, Surgical and Gynæcological Complica- tions of Pregnancy}

Edited by A. F. GutTMAcher, M.D., and J. J. Rovinsky, M.D. Pp. viii + 6r9, illustrated.

London: Baillière, Tindall and Cox. r960. I32s.

This book is a compendium on the complications of pregnancy by the staff of the Mount Sinai Hospital, New York City. It is a mine of information, covering practically any complication, common or rare, which may attack a patient during pregnancy, labour or puerperium. After each chapter there is a list of references to which the reader may refer for more detailed information, though this naturally has an American bias.

An English reader would find some of the chapters pedantic and fussy in composition. It sometimes makes hard reading. Words like hypervolemia and anesthologist would be unlikely to be met with in an English textbook.

On the whole, the book shows the general tendency of physicians today, with an over-emphasis on the laboratory and radiological investigations and polypharmacy in the way of treatment, with a disregard for the patient as a patient. Nevertheless, it is a useful book of reference for those practising obstetrics and may be relied upon to provide needed information on even the rarest complication.

\section{The Electrical Activity of the Nervous System}

MARY A. B. Brazier, B.SC., PH.D.(LOND.). Second edition. Pp. xiv + 273, illustrated. London: Pitman Medical Publishing Co. Ltd. I960. 35s.

In this work the author has brought together information about the electrical activity of individual components of the nervous system and also of the spinal cord, brain and special senses.

Though the book is intended primarily for physiology and medical students, the method of presentation is at too advanced a level for easy comprehension, and insufficient attention is given to related studies. It is more useful for workers requiring a general review of the development and present state of our knowledge in this field. There is also a very useful bibliography after each chapter. 